\title{
Association between breast-feeding and anthropometry and CVD risk factor status in adolescence and young adulthood: the Young Hearts Project, Northern Ireland
}

\author{
Valerie A Holmes ${ }^{1, *}$, Chris Cardwell ${ }^{2}$, Michelle C McKinley ${ }^{3}$, lan S Young ${ }^{3}$, \\ Liam J Murray ${ }^{2}$, Colin A Boreham ${ }^{4}$ and Jayne V Woodside ${ }^{3}$ \\ 'Nursing and Midwifery Research Unit, School of Nursing and Midwifery, Queen's University Belfast, 10 \\ Malone Road, Belfast BT9 5BN, UK: 'Epidemiology Research Group, Centre for Public Health, Queen's \\ University Belfast, Belfast, UK: ${ }^{3}$ Nutrition and Metabolism Group, Centre for Public Health, Queen's University \\ Belfast, Belfast, UK: ${ }^{4}$ Institute of Sport and Health, University College Dublin, Dublin, Ireland
}

Submitted 4 February 2009: Accepted 24 August 2009: First published online 7 0ctober 2009

\begin{abstract}
Objective: To examine the association between breast-feeding and blood pressure, anthropometry and plasma lipid profile in both adolescence and young adulthood.

Design: Longitudinal study of biological and behavioural risk factors for CVD. Setting: The Young Hearts Project, Northern Ireland.

Subjects: Schoolchildren aged 12 years and 15 years who participated in a crosssectional study of lifestyle and health, and who were followed up as young adults aged 20-25 years.

Results: There was no significant difference in height, weight, BMI, skinfold thickness measurements, blood pressure or plasma lipid profile in adolescents who had been breast-fed compared with those who had not been breast-fed. However, by the time these adolescents had reached adulthood, those who had been breast-fed were significantly taller than those who had not been breast-fed (standing height, $P=0 \cdot 013$; leg length, $P=0 \cdot 035$ ). Specifically, the breast-fed group was on average taller by $1.7 \mathrm{~cm}(95 \% \mathrm{CI} 0 \cdot 4,3 \cdot 0 \mathrm{~cm})$ and had longer legs by $1 \cdot 0 \mathrm{~cm}(95 \%$ CI $0 \cdot 1,1 \cdot 9 \mathrm{~cm})$. There was no significant difference in other anthropometric measures, blood pressure or plasma lipid profile in adults who had been breast-fed compared with those who had not been breast-fed.

Conclusions: Compared with those who had not been breast-fed, individuals who had been breast-fed were taller in adulthood. Given the known association of increased adult height with improved life expectancy, the results from the present study support a beneficial effect of breast-feeding.
\end{abstract}

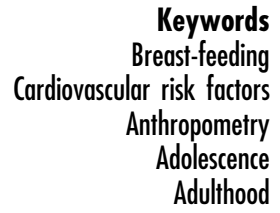

Only $35 \%$ of UK babies are being exclusively breast-fed at 1 week, $21 \%$ at 6 weeks, $7 \%$ at 4 months and $3 \%$ at 5 months ${ }^{(1)}$, despite WHO recommendations that infants should be fed breast milk exclusively for the first six months of life ${ }^{(2)}$. Although it is widely accepted that breast-feeding has numerous health benefits for both the infant and mother ${ }^{(3,4)}$, controversy remains over the benefits of breast-feeding on the incidence of adult $\mathrm{CVD}^{(5)}$ and, in particular, CVD mortality ${ }^{(6-8)}$.

Increasing evidence suggests that breast-feeding is associated with lower CVD risk factors such as serum total cholesterol (TC) and LDL cholesterol (LDL-C) ${ }^{(9-11)}$; however, the effect of breast-feeding is not clear for all known risk factors, including BMI and blood pressure ${ }^{(12-15)}$. Evidence suggests that breast-feeding in infancy may have a small effect on BMI in adolescence and adult life ${ }^{(12)}$. Breast-feeding is also associated with lower levels of TC and LDL-C in adulthood ${ }^{(6,9)}$. The magnitude of the effect of breast-feeding on blood pressure remains uncertain, and concerns have been expressed about the influence of publication bias and confounding on this relationship $^{(13,14,16)}$. Little is known about the effect of breast-feeding on height in adolescence and adulthood; however, emerging evidence points to a potential association with increased stature ${ }^{(17,18)}$.

Several recent studies have assessed the association between breast-feeding and cardiovascular risk factors in adolescence, reporting no relationship between breastfeeding and TC and LDL-C ${ }^{(9,19)}$, no relationship between breast-feeding and lower LDL-C:HDL cholesterol (HDL-C) 
ratio ${ }^{(19)}$, and no relationship between breast-feeding and lower blood pressure ${ }^{(20)}$; the persistence of these associations into adulthood is less clear. The present study examines the association between breast-feeding and blood pressure, anthropometric measures and plasma lipid profile in adolescents aged 12-15 years, and in these same individuals as young adults aged 20-25 years.

\section{Methods}

\section{Participants}

In 1989-90, a $2 \%$ representative sample of schoolchildren from Northern Ireland aged 12 years and 15 years ( $n$ 1015) participated in a cross-sectional study of lifestyle and health (Young Hearts Study 1 (YH1)) ${ }^{(21)}$. In 1992-3, 455 of the former 12-year-olds participated in a second screening (Young Hearts Study 2 (YH2)); and between October 1997 and October 1999, all original participants were invited to participate in a third screening phase (Young Hearts Study 3 (YH3)) as young adults and 489 young adults attended ${ }^{(22)}$. The present study utilises data and samples obtained at the first and third screening (YH1 and YH3) for all participants who attended the third screening ( $n$ 489). Ethical approval was obtained from the Research Ethics Committee, Queen's University Belfast, and written informed consent was obtained from all participants.

\section{Procedures}

The sampling procedure for the Young Hearts Studies has been described in detail elsewhere ${ }^{(21-23)}$. In brief, for both YH1 and YH3, information was collected on dietary intake (using the dietary history method with a trained researcher), physical activity (using a modified version of the Baecke questionnaire of habitual physical activity), smoking and drinking habits, and other lifestyle variables. Body weight was measured to the nearest $0 \cdot 1 \mathrm{~kg}$ using an electronic balance $(200 \mathrm{~kg} \times 0.1 \mathrm{~kg} ;$ SECA, Hamburg, Germany). Standing height and sitting height were measured to the nearest millimetre using a Harpenden portable stadiometer (Holtain, Crymych, UK). For measurements of height and weight, participants wore light indoor clothing and no shoes. BMI was computed as weight $(\mathrm{kg}) /[\text { height }(\mathrm{m})]^{2}$. Waist:hip ratio (WHR) was measured and used as a measure of central adiposity. Skinfold thicknesses were obtained from four sites (triceps, biceps, subscapular and suprailiac) using callipers (Holtain) and body fat composition was estimated according to the method of Durnin and Rahaman $^{(24)}$. Blood pressure was measured twice from the right arm, using a Hawksley random zero sphygmomanometer, with the participant sitting quietly for at least $5 \mathrm{~min}$; the average of these two readings was used for the current analysis.

Fasting blood samples $(40 \mathrm{ml})$ were drawn from the antecubital vein. Blood was immediately separated into whole blood, plasma/serum and buffy coat and stored as aliquots at $-70^{\circ} \mathrm{C}$ until analyses. TC and triacylglycerols from serum were measured using enzymatic assays (Boehringer Mannheim, East Sussex, UK) on a Cobas Fara centrifugal analyser. HDL-C was measured by enzymatic assay following phosphotungstate precipitation. LDL-C was calculated using the Friedewald formula ${ }^{(25)}$.

Occupational class of head of household was classified according to the Office of Population Censuses and Surveys (1990) using information gathered at YH1. Birth weight was recorded from the Child Health System records ( $n$ 456) and, where not available, birth weight as reported in a parental questionnaire was used ( $n$ 29). Birth weight standard deviation scores (SDS) were calculated as described by Freeman et $a l^{(26)}$. Information on infant feeding (breast-fed (yes/no) and duration of breastfeeding) was obtained from a parental questionnaire collected as part of YH1 ( $n$ 472). Maternal and paternal height and weight were also self-reported in this parental questionnaire, allowing the calculation of maternal and paternal BMI.

\section{Statistical analyses}

The SPSS statistical software package version $14 \cdot 0$ (SPSS Inc., Chicago, IL, USA) was used for statistical analysis. Mean and standard deviation were used to describe the continuous variables. Categorical variables were compared between the breast-fed and non-breast-fed groups using the $\chi^{2}$ test. The means of continuous variables were compared in the breast-fed and non-breast-fed groups using the independent-samples $t$ test. Multiple linear regression models were used to adjust for any difference between the breast-fed and non-breast-fed groups with respect to potential confounders either identified from the literature or identified from our analyses (sex, age, social class, birth weight SDS, gestational age, maternal height and paternal height (for height measures only); sex, age, social class, birth weight SDS, gestational age, maternal BMI and paternal BMI (for all other measures)). ANOVA was used to compare the mean of continuous variables by duration of breast-feeding and, as before, multiple linear regression models were used to adjust for potential confounders. Analysis of covariance was used to analyse differences in response between adolescence and adulthood.

\section{Results}

A total of 489 participants who participated in $\mathrm{YH} 1$ attended the YH3 screening, representing $48 \cdot 2 \%$ of the 1015 who had been originally screened. Breast-feeding information was available on 472 participants, with 101 participants $(21.4 \%)$ recorded as being breast-fed as infants. There were small but significant increases in maternal and paternal height, social class and birth weight in breast-fed infants $(P=0 \cdot 005, \quad P=0 \cdot 03$, 
Table 1 Characteristics of participants by breast-fed status: Young Hearts Project, Northern Ireland

\begin{tabular}{|c|c|c|c|c|c|}
\hline \multirow[b]{2}{*}{ Variable } & \multicolumn{2}{|c|}{ Breast-fed ( $n$ 101) } & \multicolumn{2}{|c|}{ Not breast-fed ( $n$ 371) } & \multirow[b]{2}{*}{$P$ value } \\
\hline & $n$ & $\%$ & $n$ & $\%$ & \\
\hline Male & 52 & $51 \cdot 5$ & 190 & $51 \cdot 2$ & $0.99^{*}$ \\
\hline Breast-feeding duration & & & & & - \\
\hline Less than 1 month & 28 & $27 \cdot 7$ & - & - & \\
\hline 1-3 months & 40 & $39 \cdot 6$ & - & - & \\
\hline 4-6 months & 19 & $18 \cdot 8$ & - & - & \\
\hline More than 6 months & 13 & $12 \cdot 9$ & - & - & \\
\hline Not known & 1 & $1 \cdot 0$ & - & - & \\
\hline Social class & & & & & $<0.001^{*}$ \\
\hline I & 11 & $11 \cdot 2$ & 20 & $6 \cdot 0$ & \\
\hline II & 44 & $44 \cdot 9$ & 91 & $27 \cdot 2$ & \\
\hline III non-manual & 18 & $18 \cdot 4$ & 44 & $13 \cdot 1$ & \\
\hline III manual & 21 & $21 \cdot 4$ & 126 & $37 \cdot 6$ & \\
\hline IV & 4 & $4 \cdot 1$ & 42 & $12 \cdot 5$ & \\
\hline \multirow[t]{2}{*}{ V } & 0 & 0 & 12 & $3 \cdot 6$ & \\
\hline & Mean & SD & Mean & SD & \\
\hline Age at $\mathrm{YH} 1$ (years) & $14 \cdot 0$ & $1 \cdot 57$ & $13 \cdot 9$ & $1 \cdot 51$ & $0 \cdot 37$ \\
\hline Age at $\mathrm{YH} 3$ (years) & $22 \cdot 4$ & 1.58 & $22 \cdot 6$ & 1.64 & 0.29 \\
\hline Gestational age (weeks) & $39 \cdot 6$ & $1 \cdot 10$ & $39 \cdot 4$ & $1 \cdot 77$ & $0 \cdot 21$ \\
\hline Birth weight (g) & 3494 & 452 & 3368 & 571 & 0.04 \\
\hline Maternal height $(\mathrm{cm})$ & 163 & $5 \cdot 3$ & 162 & $6 \cdot 2$ & 0.005 \\
\hline Paternal height $(\mathrm{cm})$ & 177 & $6 \cdot 5$ & 175 & $6 \cdot 7$ & 0.03 \\
\hline Maternal BMI $\left(\mathrm{kg} / \mathrm{m}^{2}\right)$ & $23 \cdot 9$ & $3 \cdot 12$ & $24 \cdot 3$ & $3 \cdot 9$ & 0.43 \\
\hline Paternal BMI $\left(\mathrm{kg} / \mathrm{m}^{2}\right)^{\prime}$ & $25 \cdot 1$ & $3 \cdot 36$ & $25 \cdot 4$ & $2 \cdot 9$ & 0.41 \\
\hline
\end{tabular}

YH1, Young Hearts Study 1; YH3, Young Hearts Study 3.

Data are presented as or $n$ and \% or as mean and standard deviation.

Comparisons were made using the independent-samples $t$ test except where indicated; ${ }^{*} P$ value based upon exact $\chi^{2}$ test.

$P=0 \cdot 001$ and $P=0 \cdot 04$, respectively), while there were no significant differences in gestational age, maternal and paternal BMI between the two groups (Table 1).

The differences in the anthropometric measures, blood pressure and lipoproteins between the adolescents attending the YH1 screening according to breast-fed status are presented in Table 2. Adolescents who had been breast-fed had significantly lower average systolic blood pressure compared with those who had not been breastfed (112 v. $115 \mathrm{mmHg}, P=0 \cdot 04)$; however, after adjustment for confounders this association was attenuated $(P=0 \cdot 23)$. There was no significant difference in height, weight, BMI, skinfold thickness measurements, diastolic blood pressure, TC or HDL-C in adolescents who had been breast-fed compared with those who had not been breast-fed.

The differences in the anthropometric measures, blood pressure and lipoproteins between the young adults in YH3 who had been breast-fed compared with those who had not been breast-fed are presented in Table 3. Adults who had been breast-fed were significantly taller (higher standing height, trunk length and leg length) than those who had not been breast-fed $(P=0 \cdot 007, P=0 \cdot 045$ and $P=0 \cdot 006$, respectively). After adjustment for potential confounding variables, including maternal and paternal height, the association remained for standing height $(P=0 \cdot 013)$ and leg length $(P=0 \cdot 035)$. Specifically, the breast-fed group was on average taller by $1.7 \mathrm{~cm}(95 \% \mathrm{CI}$ $0 \cdot 4,3 \cdot 0 \mathrm{~cm})$ and had longer legs by $1 \cdot 0 \mathrm{~cm}(95 \% \mathrm{CI} 0 \cdot 1$,
$1.9 \mathrm{~cm}$ ) than the non-breast-fed group. Furthermore, the association with height in adulthood between the breastfed and non-breast-fed groups remained after adjustment for height in adolescence $(P=0 \cdot 013)$. There was evidence that adults who had been breast-fed had slightly higher mean TC $(4 \cdot 8 v \cdot 4.5 \mathrm{mmol} / 1, P=0 \cdot 04)$ compared with those who had not been breast-fed and there was some indication of higher LDL-C $(3.0 v .2 .8 \mathrm{mmol} / \mathrm{l}$, $P=0 \cdot 07)$ when compared with those who had not been breast-fed. However, when the analyses were adjusted for potential confounding variables these associations were slightly attenuated and were not statistically significant ( $P=0.061$ and $P=0.054$, respectively).

The effect of duration of breast-feeding on anthropometric measures, blood pressure and lipoproteins in adolescents attending the $\mathrm{YH} 1$ screening and $\mathrm{YH} 3$ screening was examined. There was no significant association between these measures and duration of breastfeeding in the YH1 or YH3 participants (data not shown).

\section{Discussion}

In the current longitudinal study, individuals who had been breast-fed were, on average, $1.7 \mathrm{~cm}$ taller in adulthood than those who had not been breast-fed, a difference that was not observed during adolescence. The difference in standing height associated with breastfeeding, that was apparent in adulthood, seemed to be 
owing to longer leg length rather than trunk length. Adolescents who had been breast-fed had lower average systolic blood pressure compared with those who had not been breast-fed; however this association was attenuated after adjusting for confounding factors. Furthermore, adolescents who had been breast-fed were similar to those who had not been breast-fed for measures of weight, height, BMI, skinfold thickness and lipoproteins. In adulthood, those who had been breast-fed had higher TC and LDL-C than those who had not been breast-fed, although there was less evidence of this association after adjusting for confounding factors. Young adults who had been breast-fed were similar to those who had not been breast-fed in terms of weight, BMI, skinfold thickness, blood pressure, HDL-C and TAG. Birth weight was significantly different between individuals who had/had not been breast-fed; however, this was included as a potential confounding factor and adjusted for in regression analyses.

Our findings of an association between increased height, and in particular increased leg length, in adults who had been breast-fed confirm the findings of the Boyd-Orr cohort study(18). The Boyd-Orr cohort also reported an association between breast-feeding and increased height in childhood (2-15 years), whereas we did not find any such association at the adolescent stage (mean age 14 years) in the present study. However, our study focused on a specific adolescent year group (mean age 14 (SD 1.5) years), whereas the Boyd-Orr cohort reported data for childhood as a whole including children aged 2-15 years. Furthermore, since the Boyd-Orr cohort was born in the 1920s and 1930s, compared with the 1980s in the present study, there are likely to be differences in environmental factors that could influence the results. For example, the alternatives to breast milk that were offered to infants in the 1920s and 1930s and the exact composition of infant formulas that were available during this time are likely to be very different from those available 60 years later. Indeed, Martin et ll $^{(18)}$ query the contemporary relevance of their results. It is important to note, however, that the association of breast-feeding and height in the Boyd-Orr cohort was more pronounced after mid-childhood, suggesting that breast-feeding may differentially influence growth at puberty compared with early life ${ }^{(18)}$. The present study in a contemporary population indicates that the association between breastfeeding and height may not become apparent until early adulthood. Martin et $a l .{ }^{(18)}$ suggest a number of reasons which may explain the association between breastfeeding and increased stature later in life, including setting of the growth trajectory through optimum nutrition ${ }^{(27)}$, protection against enteric or respiratory infections and psychological effects relating to maternal bonding. The fetal origins hypothesis ${ }^{(28)}$ contends that physiological or metabolic programming occurs during critical periods of ontogeny and determines health later in life. In line with 
Table 3 Anthropometric measures, blood pressure and lipoproteins in breast-fed and non-breast-fed groups during young adulthood (20-25 years; YH3): Young Hearts Project, Northern
Ireland Ireland

\begin{tabular}{|c|c|c|c|c|c|c|c|c|c|c|}
\hline & \multicolumn{2}{|c|}{$\begin{array}{l}\text { Breast-fed } \\
\quad(n \text { 101) }\end{array}$} & \multicolumn{2}{|c|}{$\begin{array}{l}\text { Not breast-fed } \\
\quad(n 371)\end{array}$} & \multirow{2}{*}{$\begin{array}{l}\text { Difference in mean } \\
\text { (breast-fed minus not breast-fed) }\end{array}$} & \multirow{2}{*}{$95 \% \mathrm{Cl}$} & \multirow[b]{2}{*}{$P$ value* } & \multirow{2}{*}{$\begin{array}{l}\text { Adjusted difference in meant } \\
\text { (breast-fed minus not breast-fed) }\end{array}$} & \multirow[b]{2}{*}{$95 \% \mathrm{Cl}$} & \multirow[b]{2}{*}{ Adjusted $P$ value } \\
\hline & Mean & SD & Mean & SD & & & & & & \\
\hline Age at time of participation (years) & $22 \cdot 4$ & $1 \cdot 6$ & $22 \cdot 6$ & $1 \cdot 7$ & $-0 \cdot 2$ & $-0 \cdot 6,0.2$ & 0.294 & & & \\
\hline Standing height $(\mathrm{cm})$ & $173 \cdot 6$ & $9 \cdot 1$ & $170 \cdot 8$ & $9 \cdot 3$ & $2 \cdot \overline{8}$ & $0 \cdot 8,4 . \overline{9}$ & 0.007 & $1 \cdot 7$ & $0.4,3 \cdot 0$ & 0.013 \\
\hline Trunk length (cm) & $90 \cdot 7$ & $4 \cdot 2$ & $89 \cdot 7$ & $4 \cdot 6$ & $1 \cdot 0$ & $0 \cdot 0,2 \cdot 0$ & 0.045 & $0 \cdot 7$ & $-0 \cdot 1,1 \cdot 5$ & $0 \cdot 104$ \\
\hline Leg length $(\mathrm{cm})$ & $82 \cdot 9$ & $5 \cdot 9$ & $81 \cdot 1$ & $5 \cdot 8$ & $1 \cdot 8$ & $0 \cdot 5,3 \cdot 1$ & 0.006 & $1 \cdot 0$ & $0.07,1.9$ & 0.035 \\
\hline Weight $(\mathrm{kg})$ & $71 \cdot 3$ & $13 \cdot 1$ & $69 \cdot 7$ & $12 \cdot 9$ & $1 \cdot 6$ & $-1 \cdot 3,4 \cdot 4$ & 0.285 & 2.5 & $-0 \cdot 2,5 \cdot 2$ & 0.069 \\
\hline $\mathrm{BMI}\left(\mathrm{kg} / \mathrm{m}^{2}\right)$ & $23 \cdot 5$ & $3 \cdot 4$ & $23 \cdot 8$ & $3 \cdot 8$ & -0.3 & $-1 \cdot 1,0.5$ & 0.467 & 0.2 & $-0 \cdot 7,1 \cdot 0$ & 0.693 \\
\hline WHR & 0.78 & 0.07 & 0.79 & 0.07 & 0.00 & $-0.02,0.01$ & 0.813 & 0.00 & $-0.01,0.01$ & $0 \cdot 882$ \\
\hline \multicolumn{11}{|l|}{ Skinfold thickness (mm) } \\
\hline Biceps & $7 \cdot 4$ & $4 \cdot 3$ & $7 \cdot 5$ & 4.9 & -0.2 & $-1 \cdot 3,0.9$ & 0.746 & $0 \cdot 1$ & $-0 \cdot 9,1 \cdot 2$ & 0.802 \\
\hline Triceps & $13 \cdot 3$ & $6 \cdot 5$ & $14 \cdot 1$ & $7 \cdot 1$ & -0.9 & $-2 \cdot 4,0 \cdot 7$ & 0.268 & 0.07 & $-1 \cdot 4,1 \cdot 5$ & 0.921 \\
\hline Subscapular & $13 \cdot 5$ & $5 \cdot 2$ & $14 \cdot 1$ & $6 \cdot 0$ & $-0 \cdot 6$ & $-1 \cdot 8,0 \cdot 7$ & 0.393 & 0.2 & $-1 \cdot 1,1 \cdot 6$ & 0.730 \\
\hline Suprailiac & $15 \cdot 8$ & $6 \cdot \overline{6}$ & $15 \cdot 9$ & $7 \cdot 4$ & -0.1 & $-1 \cdot 7,1 \cdot 5$ & 0.870 & $0 . \overline{5}$ & $-1 \cdot 3,2 \cdot 3$ & 0.567 \\
\hline SBP (mmHg) & $113 \cdot 4$ & $11 \cdot 7$ & $113 \cdot 4$ & $12 \cdot 9$ & 0.01 & $-2 \cdot 8,2 \cdot 8$ & 0.993 & 0.3 & $-2 \cdot 5,3 \cdot 2$ & $0 \cdot 829$ \\
\hline DBP (mmHg) & 74.9 & $9 \cdot 2$ & $73 \cdot 7$ & $9 \cdot 4$ & $1 \cdot 3$ & $-0 \cdot 8,3 \cdot 3$ & 0.233 & 1.5 & $-0 \cdot 8,3 \cdot 8$ & $0 \cdot 193$ \\
\hline $\mathrm{TC}(\mathrm{mmol} / \mathrm{l})$ & $4 \cdot 8$ & $0 . \overline{9}$ & $4 \cdot 5$ & 0.9 & 0.2 & $0.01,0.4$ & 0.039 & 0.2 & $-0.01,0.5$ & 0.061 \\
\hline HDL-C (mmol/l/) & $1 \cdot 4$ & 0.4 & $1 \cdot 4$ & $0 \cdot 4$ & $0 \cdot 0$ & $-0.1,0.08$ & 0.953 & -0.03 & $-0.1,0.07$ & 0.528 \\
\hline LDL-C (mmol/l') & $3 \cdot 0$ & 0.8 & $2 \cdot 8$ & $0 \cdot 8$ & 0.2 & $-0.01,0.4$ & 0.065 & 0.2 & $-0.004,0.4$ & 0.054 \\
\hline TAG $(\mathrm{mmol} / \mathrm{l})$ & 0.9 & 0.4 & $0 \cdot 8$ & 0.4 & 0.08 & $-0.02,0.2$ & $0 \cdot 112$ & 0.08 & $-0.03,0.2$ & $0 \cdot 144$ \\
\hline
\end{tabular}

YH3 Young Hearts Study 3; WHR, waist:hip ratio; SBP, systolic blood pressure; DBP, diastolic blood pressure; TC, total cholesterol; HDL-C, HDL cholesterol; LDL-C, LDL cholesterol.

*Andependent-samples $t$ test. (all other measures). 
this, and consistent with results of the present study, Dietz $^{(29)}$ proposes that the consequences of infant feeding may only become apparent at some stage later in development rather than in early childhood, as suggested by an animal study where effects of overfeeding in infancy only became apparent some years later ${ }^{(30)}$. The positive association between breast-feeding and stature in the present study naturally raises the possibility that the precise duration of breast-feeding may have an important influence on this relationship; however, this could not be adequately examined in the current study, perhaps owing to small numbers. A study in the literature in Brazilian young adult men, aged 18 years ( $n$ 2250), has reported a borderline association $(P=0.06)$ between duration of breast-feeding and height ${ }^{(17)}$.

We found no significant association between breastfeeding and BMI in adolescence or adulthood. A recent quantitative systematic review examining the influence of breast-feeding on obesity in later life demonstrated a protective effect of breast-feeding on $\mathrm{BMI}^{(12)}$; however, the authors state that the precise magnitude of this effect is still unclear and that the impact of confounding and publication bias on this finding requires closer examination. It is worth noting that the small difference observed in the systematic review lies within our 95\% confidence intervals for the difference in BMI between breast-fed and non-breast-fed participants, and therefore the two studies are compatible in their findings.

We found no association between breast-feeding and blood pressure in adolescence or adulthood; however, two recent meta-analyses, mostly examining cross-sectional data, do report an association between breastfeeding and systolic ${ }^{(13,14)}$ or diastolic blood pressure ${ }^{(14)}$ in later life. Both indicate that the effect is likely to be small (pooled mean difference 0.5-1.4 mmHg) and, again, may be strongly influenced by confounding and bias. A unique study in the literature by Singhal et $a l^{(20)}$ measured blood pressure at age 13-16 years in a group of children who had been born prematurely and had participated at birth in a randomised trial of banked breast milk $v$. formula. Children assigned to receive banked breast milk had significantly lower mean arterial blood pressure (between-group difference of $4 \cdot 2 \mathrm{mmHg}$ ) at age 13-16 years compared with those assigned to receive preterm formula. Although we were able to show lower average systolic blood pressure in adolescents who had been breast-fed compared with those who had not been breast-fed, this association was attenuated after adjusting for confounding factors.

In agreement with a meta-analysis examining the effects of infant feeding on cholesterol in children and adolescents (1-16 years) ${ }^{(9)}$, we found no association between breast-feeding and TC or LDL-C at the adolescent stage of life. The same meta-analysis reported lower mean TC and LDL-C in adults ( $\geq 17$ years) who had been breast-fed $^{(9)}$. In contrast, we found higher TC and LDL-C in breast-fed adults compared with those who had not been breast-fed, although this association was attenuated and lost significance when the analysis was adjusted for confounding factors. While not consistent with the majority of studies, two other studies in adults have also shown an association, albeit non-significant, between breast-feeding and increased lipoproteins ${ }^{(6,8)}$. Possible explanations for these differing results include differences in the alternatives to breast-feeding, chance or residual confounding $^{(8,9)}$.

An important strength of the current study is the length of follow-up; there are few studies in the literature where follow-up information is available into adulthood. This allowed us to examine associations between breastfeeding, anthropometry and cardiovascular risk factor status at both the adolescent and adult life stages in a representative sample of young people from Northern Ireland, a region of high coronary mortality. The wide spectrum of cardiovascular and anthropometric measures recorded and the ability to control for many confounding factors, such as gestational age, birth weight and maternal and paternal height and BMI, are also important strengths of the study. As with all studies of this nature, however, the limitations must be recognised. First, the numbers studied are relatively small, making it difficult to examine any effect of duration of breast-feeding on the parameters examined. Second, we had no information on the exclusivity of breast-feeding and were unable to examine differences in those who had been exclusively $v$. partially breast-fed. Although the classification of 'breast-fed' or 'not breast-fed' was based on questionnaire data collected from parents when the children were aged, on average, 14 years, the accuracy of such data has shown to be valid for up to 20 years after birth ${ }^{(31)}$. Third, we had no information on weaning practices among those studied and could not assess the importance of age of weaning, although it is unclear if age of weaning is a significant confounder $^{(8)}$. Fourth, given the nature of epidemiological studies, the possibility of residual or unobserved confounding by this or other factors can only be minimised. Finally, in view of the small numbers of participants, the wide confidence intervals and the multiple comparisons carried out, the positive association between stature and breast-feeding must be interpreted with caution and may be a chance finding.

The current study did not find an association between breast-feeding and cardiovascular risk factor status; there was, however, a significant association between breastfeeding and increased adult stature. Evidence indicates that height is inversely associated with CVD mortality risk, respiratory disease risk and stroke, although results are inconsistent for risk of cancer ${ }^{(32)}$. The findings reported here confirm previous reports relating to breast-feeding and stature ${ }^{(18)}$ and, given the association of increased height with improved life expectancy ${ }^{(32,33)}$, provide further evidence for the promotion of breast-feeding. 
The current study did not differentiate between exclusive and non-exclusive breast-feeding and duration of breastfeeding was not taken into account, yet an effect of breast-feeding on adult stature was still apparent. These results suggest that any breast-feeding in infancy, and not just exclusive breast-feeding to 6 months, may be associated with increased height in adulthood; however, this would need to be examined in an adequately powered data set. The WHO recommends that infants should be fed breast milk exclusively for the first six months of life ${ }^{(2)}$. While such recommendations are to be encouraged owing to the numerous health benefits of breastfeeding for mother and infant, less than $3 \%$ of infants in the UK are breast-fed exclusively to 6 months ${ }^{(2)}$. It is important that mothers continue to be made aware that any breast-feeding is more beneficial than no breastfeeding, thus reducing the guilt experienced by mothers who are not able, for various reasons, to exclusively breast-feed for 6 months ${ }^{(34)}$.

In summary, we have shown that breast-feeding is associated with increased adult height. Given the known association between increased adult height and improved life expectancy, the results from the present study add to the literature supporting a beneficial effect of breastfeeding on health-related parameters.

\section{Acknowledgements}

Sources of funding: The study was supported by the British Heart Foundation; the Wellcome Trust; Northern Ireland Chest, Heart and Stroke; and the Department of Health and Social Services in Northern Ireland. Conflict of interest declaration: None of the authors had a conflict of interest. Authorship responsibilities: V.A.H., J.V.W. and M.C.M. contributed to the implementation of the analysis. I.S.Y., L.J.M. and C.A.B. were responsible for the original study design. C.C., V.A.H. and J.V.W. undertook statistical analyses of the data. V.A.H. wrote the first draft of the paper and all authors were involved in revisions of the paper.

\section{References}

1. Scientific Advisory Committee on Nutrition (2008) Infant Feeding Survey 2005: A Commentary on Infant Feeding Practices in the UK: Position Statement. London: TSO.

2. Saadeh RJE (editor) (1993) Breastfeeding: The Technical Basis and Recommendations for Action. Breastfeeding in the 1990s Technical Meeting, June 1990. Geneva: WHO.

3. Davis MK (2001) Breastfeeding and chronic disease in childhood and adolescence. Pediatr Clin North Am 48, 125-141.

4. Schack-Nielsen L, Larnkjaer A \& Michaelsen KF (2005) Long term effects of breastfeeding on the infant and mother. Adv Exp Med Biol 569, 16-23.

5. Greer FR (2005) Breastfeeding and cardiovascular disease: where's the beef? Pediatrics 115, 1765.
6. Fall CH, Barker DJ, Osmond C et al. (1992) Relation of infant feeding to adult serum cholesterol concentration and death from ischaemic heart disease. BMJ 304, 801-805.

7. Martin RM, Davey Smith G, Mangtani P et al. (2004) Breastfeeding and cardiovascular mortality: the Boyd Orr cohort and a systematic review with meta-analysis. Eur Heart J 25, 778-786.

8. Martin RM, Ben-Shlomo Y, Gunnell D et al. (2005) Breast feeding and cardiovascular disease risk factors, incidence, and mortality: the Caerphilly study. J Epidemiol Community Health 59, 121-129.

9. Owen CG, Whincup PH, Odoki K et al. (2002) Infant feeding and blood cholesterol: a study in adolescents and a systematic review. Pediatrics 110, 597-608.

10. Owen CG, Martin RM, Whincup PH et al. (2005) Effect of infant feeding on the risk of obesity across the life course: a quantitative review of published evidence. Pediatrics 115, 1367-1377.

11. Ravelli AC, van der Meulen JH, Osmond C et al. (2000) Infant feeding and adult glucose tolerance, lipid profile, blood pressure, and obesity. Arch Dis Child 82, 248-252.

12. Owen CG, Martin RM, Whincup PH et al. (2005) The effect of breastfeeding on mean body mass index throughout life: a quantitative review of published and unpublished observational evidence. Am J Clin Nutr 82, 1298-1307.

13. Owen CG, Whincup PH, Gilg JA et al. (2003) Effect of breast feeding in infancy on blood pressure in later life: systematic review and meta-analysis. BMJ 327, $1189-1195$.

14. Martin RM, Gunnell D \& Smith GD (2005) Breastfeeding in infancy and blood pressure in later life: systematic review and meta-analysis. Am J Epidemiol 161, 15-26.

15. Gunnarsdottir I, Aspelund T, Birgisdottir BE et al. (2007) Infant feeding patterns and midlife erythrocyte sedimentation rate. Acta Paediatr 96, 852-856.

16. Martin RM, Ness AR, Gunnell D et al.; ALSPAC Study Team (2004) Does breast-feeding in infancy lower blood pressure in childhood? The Avon Longitudinal Study of Parents and Children (ALSPAC). Circulation 109, 1259-1266.

17. Victora CG, Barros F, Lima RC et al. (2003) Anthropometry and body composition of 18 year old men according to duration of breast feeding: birth cohort study from Brazil. BMJ 327, 901.

18. Martin RM, Smith GD, Mangtani P et al. (2002) Association between breast feeding and growth: the Boyd-Orr cohort study. Arch Dis Child Fetal Neonatal Ed 87, F193-F201.

19. Singhal A, Cole TJ, Fewtrell M et al. (2004) Breastmilk feeding and lipoprotein profile in adolescents born preterm: follow-up of a prospective randomised study. Lancet 363, 1571-1578.

20. Singhal A, Cole TJ \& Lucas A (2001) Early nutrition in preterm infants and later blood pressure: two cohorts after randomised trials. Lancet 357, 413-419.

21. Boreham C, Savage JM, Primrose D et al. (1993) Coronary risk factors in schoolchildren. Arch Dis Child 68, 182-186.

22. Gallagher AM, Savage JM, Murray LJ et al. (2002) A longitudinal study through adolescence to adulthood: the young hearts project, Northern Ireland. Public Health 116, 332-340.

23. Boreham C, Twisk J, Murray L et al. (2001) Fitness, fatness, and coronary heart disease risk in adolescents: the Northern Ireland young hearts project. Med Sci Sports Exerc 33, 270-274.

24. Durnin JV \& Rahaman MM (1967) The assessment of the amount of fat in the human body from measurements of skinfold thickness. Br J Nutr 21, 681-689.

25. Friedewald WT, Levy RI \& Fredrickson DS (1972) Estimation of the concentration of low-density lipoprotein cholesterol in plasma, without use of the preparative ultracentrifuge. Clin Chem 18, 499-502. 
26. Freeman JV, Cole TJ, Chinn S et al. (1995) Cross sectional stature and weight reference curves for the UK, 1990. Arch Dis Child 73, 17-24.

27. Rogers IS, Emmett PM \& Golding J (1997) The growth and nutritional status of the breast-fed infant. Early Hum Dev 49, Suppl., S157-S174.

28. Moor V \& Davies M (2001) Early life influences on later health: the role of nutrition. Asia Pac J Clin Nutr 10, 113-117.

29. Dietz WH (2001) Breastfeeding may help prevent childhood overweight. JAMA 285, 2506-2507.

30. Lewis DS, Bertrand HA, McMahan CA et al. (1986) Preweaning food intake influences the adiposity of young adult baboons. J Clin Invest 78, 899-905.

31. Kark JD, Troya G, Friedlander Y et al. (1984) Validity of maternal reporting of breast feeding history and the association with blood lipids in 17 year olds in Jerusalem. J Epidemiol Community Health 38, 218-225.

32. Davey Smith G, Hart C, Upton M et al. (2000) Height and risk of death among men and women: aetiological implications of associations with cardiorespiratory disease and cancer mortality. J Epidemiol Community Health 54, 97-103.

33. Lee CM, Barzi F, Woodward M et al:; for The Asia Pacific Cohort Studies Collaboration (2009) Adult height and the risks of cardiovascular disease and major causes of death in the Asia-Pacific region: 21000 deaths in 510000 men and women. Int J Epidemiol 38, 1060-1071.

34. Mozingo JN, Davis MW, Droppleman PG et al. (2000) 'It wasn't working'. Women's experiences with shortterm breastfeeding. MCN Am J Matern Child Nurs 25, $120-126$. 